\title{
Prescreening bacterial colonies for bioactive molecules with Janus plates, a SBS standard double-faced microbial culturing system
}

\author{
Marina Sánchez-Hidalgo • Javier Pascual • Mercedes de la Cruz • \\ Jesús Martín · Gary S. Kath · Janet M. Sigmund • Prakash Masurekar • \\ Francisca Vicente $\cdot$ Olga Genilloud $\cdot$ Gerald F. Bills
}

Received: 6 February 2012/Accepted: 24 April 2012/Published online: 5 May 2012

(C) The Author(s) 2012. This article is published with open access at Springerlink.com

\begin{abstract}
Despite the availability of many culturebased antibiotic screening methods, the lack of sensitive automated methods to identify functional molecules directly from microbial cells still limits the search for new biologically active compounds. The effectiveness of antibiotic detection is influenced by the solubility of the assayed compounds, indicator strain sensitivity, culture media and assay configuration. We describe a qualitative high throughput
\end{abstract}

Electronic supplementary material The online version of this article (doi:10.1007/s10482-012-9746-7) contains supplementary material, which is available to authorized users.

M. Sánchez-Hidalgo · J. Pascual · M. de la Cruz J. Martín · F. Vicente · O. Genilloud · G. F. Bills (ه) Fundación MEDINA, Centro de Excelencia en Investigación de Medicamentos Innovadores en Andalucía, Avda. del Conocimiento 3, Parque Tecnológico de Ciencias de la Salud, 18100 Armilla, Granada, Spain e-mail: gerald.bills@medinaandalucia.es

G. S. Kath

Design-To-Prototype LLC, 2671 Sky Top Drive, Scotch Plains, NJ 07076, USA

J. M. Sigmund

Natural Products Discovery Institute, 3805 Old Easton

Road, Doylestown, PA 18902, USA

P. Masurekar

Department of Plant Biology \& Pathology, Rutgers University, Foran Hall, Cook Campus 59 Dudley Rd., New Brunswick, NJ 08901, USA screening system for detecting cell-perturbing molecules from bacterial colonies employing two opposed agar layers sequentially formed in prototype Society for Biomolecular Screening (SBS) plates, named Janus plates. Direct assay of microbial colonies against target organisms in opposed agar layers overcomes some of the limitations of agar overlay methods. The system enables the rapid detection of extracellular cell-perturbing molecules, e.g., antibiotics, excreted directly from environmental isolates. The source bacterial colonies remain separate from the target organism. The growth layer is prepared and grown independently, so environmental strains can be grown for longer intervals, at temperatures and in media that favor their growth and metabolite expression, while the assay layer with pathogens, usually requiring nutrient-rich medium and elevated temperatures, are added later. Colonies to be tested can be precisely arrayed on the first agar surface, thus avoiding dispersion and disturbance of potential antibiotic-producing colonies by overlaying agar with the target strain. The rectangular SBS configuration facilitates factorial replication of dense microbial colony arrays for testing with multiple assays and assay conditions employing robotic colony pickers and pin tools. Opposed agar layers only slightly reduced the effectiveness for detecting growth inhibition from pure antibiotics compared to single-layer agar diffusion assays. The Janus plate enabled an automation-assisted workflow where a lone operator can effectively identify and accumulate bioactive soil 
bacterial strains within a few weeks. We also envisage the method's utility for functional prescreening colonies of clones from genomic and metagenomic libraries or improved strains originating from mutagenized cells.

Keywords Agar-diffusion assay · Agar-overlay assay - Antibiotic - Automation · Katanosins · Lutri plate $\cdot$ Lysobacter Perturbagens .

Secondary metabolites

\section{Introduction}

Comparative genomics have demonstrated that the capacity of bacteria to produce secondary metabolites, antibiotics and other small bioactive molecules varies enormously, ranging from species having no capacity to those exceeding 30 different biosynthetic routes in cellularly differentiated bacteria with large genomes, e.g., myxobacteria and the actinomycetes (Donadio et al. 2007; Davies and Ryan 2011; Udwary et al. 2011). Antimicrobial activity can be a surrogate measurement for the ability of small molecules to interfere with or modulate cellular processes. Such molecules are defined as antibiotics when they negatively affect the growth of microbes (Davies 1990; Davies et al. 2006; Davies and Ryan 2011), or they can be more broadly defined as "perturbagens" if they modulate cell signaling pathways and cell growth and development in model organisms, including humans (Lamb 2007). Improved methods for rapid detection of functional molecules could expand the available chemistry pool and lead to discovery of new applications for small molecules in microbial and human cell biology.

The distinctive morphology of myxobacteria and actinomycetes can steer their preliminary selection for testing their potentially useful chemistry; however, the predominately featureless phenotypes of unicellular bacteria from soil, water and other substrata offer relatively few visual clues to guide the selection of biosynthetically capable strains (Gross and Loper 2009; Gram et al. 2010). However, direct prescreening of bacterial cells for their ability to produce antibiotics and perturbagens (Yim et al. 2007; Davies and Ryan 2011; Phelan et al. 2012) could circumvent laborious testing of shake-flask extracts from multitudes of bacterial strains and redirect resources to informed experimentation with the most biosynthetically capable species. That all biosynthetically capable bacteria would express their antibiotics in agar culture would be an unrealistic expectation. Nonetheless, direct microbial cell or colony assays can discriminate biosynthetically capable bacteria from those bacteria failing to produce antibiotics in vitro or those potentially lacking antibiotic biosynthetic pathways (Baltz et al. 2008; Gram et al. 2010; Wietz et al. 2010). Active strains can be funneled into enriched collections allowing resources for downstream fermentations and scale up to focus on prescreened bacteria with antibiotic phenotypes. The prescreening assay thus becomes a critical entry point into downstream processes and determines the frequency and characteristics of the antibiotic-producing bacteria selected for downstream study. Specificity and thresholds can be manipulated by either using overly sensitive or resistant assay or reporter strains, though caution must be exercised not to overload the process by causing artifacts or not to exclude interesting actives with highly insensitive strains.

Since the inception of the modern antibiotic era, many inventive agar diffusion methods have been developed to detect and measure the antimicrobial activity of microorganisms (Rios et al. 1988). These methods are unified around the observation that when a compound with biological activity diffuses through an agar layer homogeneously seeded with a target organism, and after incubation and growth of the target organisms, a clear to diffuse zone of inhibition (ZOI) radiates from the point of compound application. Agar diffusion assays remain popular because of their relative simplicity, low sample consumption and the capacity to test multiple compounds, concentrations, and mixtures from diverse sources in parallel against single or multiple microorganisms. Although not quantitative, these methods can be standardized by stringently controlling multiple factors (medium composition, microorganism sensitivity, extraction method, $\mathrm{pH}$, solubility, etc.) to provide comparative data on antimicrobial spectra and potencies (Anonymous 1977; Bauer et al. 1988; Blom et al. 1997).

Agar overlay assays are well-established variants of agar diffusion assays that can rapidly prescreen environmental bacterial colonies (Nkanga and Hagedorn 1978; Furumai et al. 1993; Hayakawa et al. 2004; Shnit-Orland and Kushmaro 2009) or clones from metagenomic libraries (Brady 2007; Craig et al. 2010) 
for their ability to produce cell-penetrable antibiotics. In these methods, the target bacterium or yeast is homogeneously mixed in partially cooled agar and gently poured over the surface of a first layer previously inoculated with potential antimicrobial producer strains. The methods exploit tridimensional diffusion gradients; excreted antibiotics are detected by ZOIs forming on the upper side of the second agar layer (Gratia and Fredericq 1946; Gratia 1947; Nkanga and Hagedorn 1978; Williams et al. 1983; Hayakawa et al. 2004; Shnit-Orland and Kushmaro 2009). A frustrating shortcoming of these methods has been the disturbance and mixing of colonies upon adding the second layer, thus cross-contaminating and obscuring results, while complicating the isolation of the active bacterial colonies from the assay plate. To overcome cross contaminations, other variations of the agar overlay assay that incubate various kinds of inverted colony plates placed onto assay plates (Kekessy and Piguet 1970; Somkuti and Steinberg 2002) or that spot colonies or directly onto assay plates (Gram et al. 2010; Wietz et al. 2010) have been improvised.

To the best of our knowledge, the first device specifically designed to carry out an opposed twolayer agar assay, thus abbreviating the colony-toactive workflow, was the Lutri plate (former Lutri Plate, Inc. Starkville, MS, USA). It was a two-sided Petri plate-like device that sequentially created opposed agar layers for assaying the effects of microbes in one layer on the microbe growing in the other (Brown 1982; Colwell and Speidel 1985; Kang and Siragusa 1999). With this system, compounds excreted by organisms growing on one kind of agar diffused through the agar to affect an organism growing on another kind of agar in the opposing layer. An advantage of this method was that addition of a second assay layer did not disturb the first layer, while molecules could diffuse freely between both. However, to our knowledge, Lutri plates or any equivalent design are no longer manufactured or sold. Furthermore, the Lutri plate's round design predated modern liquid handling and SBS plate robotics and would be incompatible with today's high throughput screening equipment that are exclusively based on the SBS footprint.

A prototype double-sided culture plate, named a Janus plate after the two-faced Roman god, and inspired by the design of the Lutri plate was developed collaboratively with NUNC (www.nuncbrand.com).
The plate enables growth of microorganisms on two opposed solid medium surfaces. The plate's SBS footprint is the same as a rectangular NUNC OmniTray plate (96-well footprint, $128 \times 85 \mathrm{~mm}$ ). Like the Lutri plate, microbial antibiotics excreted into the first medium are detected by applying a second agar layer incorporating a target bacterium or yeast and observing ZOIs after incubation. Back-to-back agar layers configured in an OmniTray format offers several advantages over overlay techniques, including high test colony density, minimal cell disturbance by heating or pouring agar overlays, and compatibility with automated pipetting stations and colony picking robots.

Because most bacterially produced antibiotics act extracellularly, their activity can be detected at the bacterial colony interface or after its diffusion from the vicinity of a colony. Therefore, we sought a high throughput solution that would facilitate prescreening large populations of bacterial colonies in situations where the probability of antibiosis was infrequent. We compare the sensitivity of the Janus plate system with that of a single agar-layer antibiotic screening methods and describe a workflow for searching for antibiotics and perturbagens from bacterial colonies from environmental samples and that would also be appropriate for functional screening of clones from metagenomic libraries or mutagenized cells. To our knowledge, we describe the first high throughput prescreening tool employing the Lutri plate concept (Brown 1982) and hope that it will stimulate further efforts toward miniaturized high throughput screening from natural bacterial populations and from recombinant strains.

\section{Materials and methods}

Description and preparation of Janus and OmniTray plates

The Janus plate design (limited prototype manufactured by NUNC, Nalge Nunc International, Rochester, NY, USA) was based on the Lutri plate system (Brown 1982; Colwell and Speidel 1985) but was reengineered in polystyrene plastic to SBS standard dimensions to enable automated management (Fig. 1). A first medium layer (40 ml, $2 \%$ agar) was poured onto one surface supported by a removable plastic platform (Fig. 1e, f). The agar was solidified around a rigid 
scaffold formed by two transverse ribs and a peripheral ledge (all $3 \mathrm{~mm}$ wide, Fig. 1). The first set of organisms was inoculated on this layer and incubated. After incubation, the plate was briefly chilled to $4{ }^{\circ} \mathrm{C}$ to harden the agar. The plate was inverted and the platform was removed (Fig. 1e, f). A second layer of media (30 ml, $1.5 \%$ agar) containing the target strain was poured across the lower surface of the first layer.

The same media were added in parallel to OmniTray plates (NUNC, $40 \mathrm{ml}, 2 \%$ agar) for comparisons.
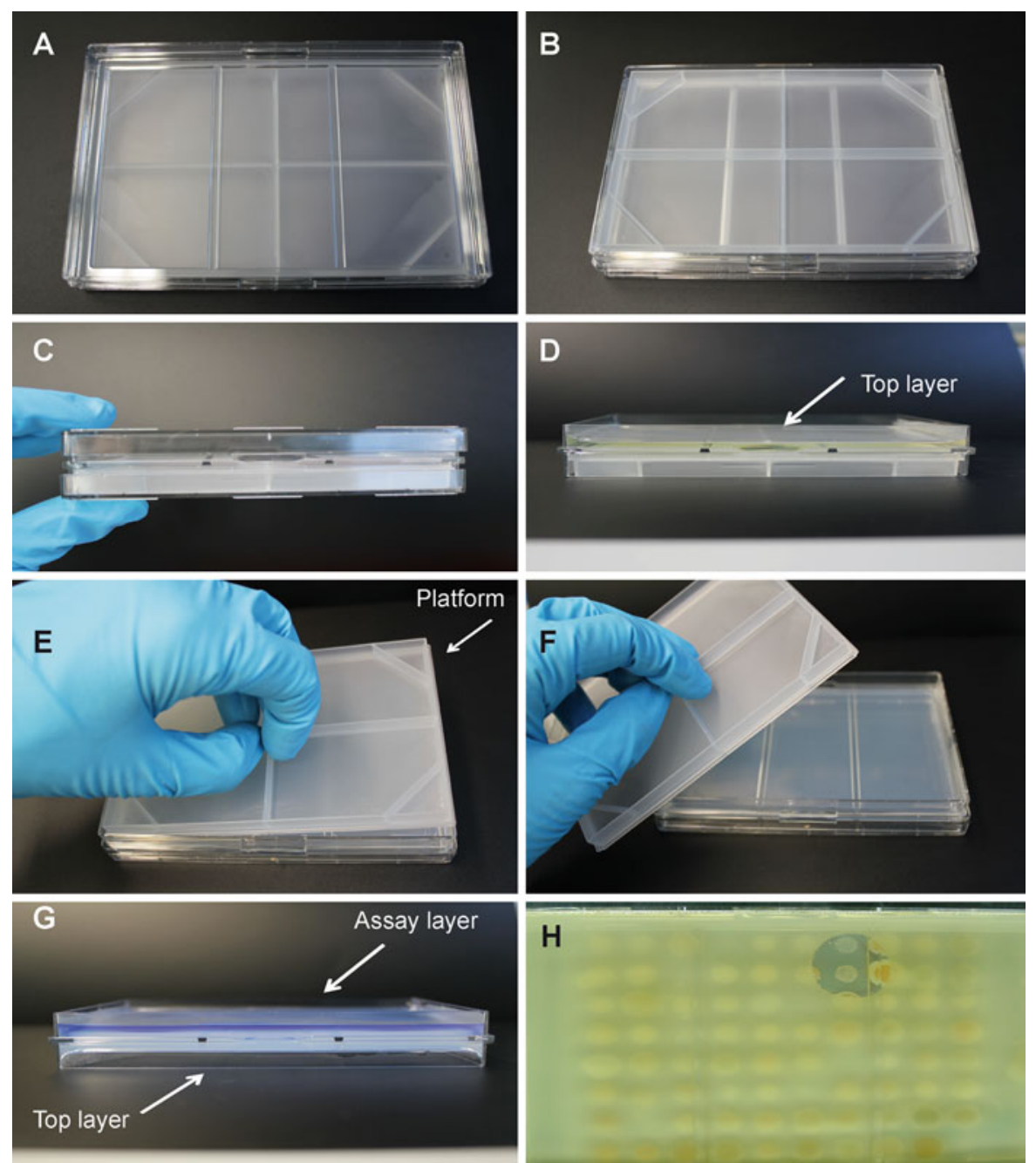

Fig. 1 Description of Janus plates. Top view (a), bottom view (b) and side view with closed lids (c), view of first agar layer added to Janus plate. Isolation agar layer is poured onto top surface (d) supported by a removable plastic platform and producer organisms are incubated. After incubation, the plate is
Growth of antibiotic-producing and target strains and their media

The capacity of known antibiotic-producing Streptomyces strains for producing ZOIs was evaluated in Janus plates. Antibiotic-producing and target strains are described in Table 1. Reference strains from the Japan Collection of Microorganisms (www.jcm. riken.jp) reported to produce amphotericin $\mathrm{B}$, tetracycline, oxytetracycline, or kanamycin were selected.

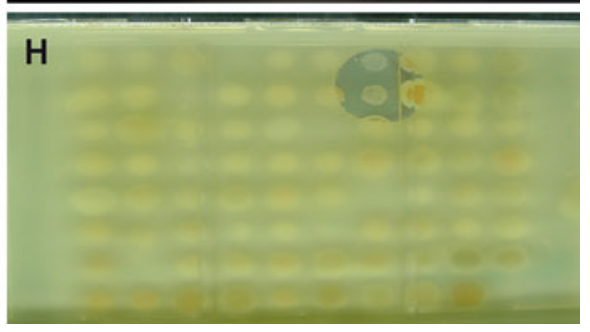

chilled to harden the agar, then inverted and the platform is removed $(\mathbf{e}, \mathbf{f})$. A second layer of media containing the target strain is poured across the lower surface of the first layer with lids removed (g). Zones of inhibition are visualized in the assay layer (h) 
Table 1 Target and antibiotic-producing strains used in Janus plate demonstration experiments

\begin{tabular}{|c|c|c|}
\hline Species & $\begin{array}{l}\text { Strain } \\
\text { number }^{\mathrm{a}}\end{array}$ & Assay function \\
\hline $\begin{array}{l}\text { Candida } \\
\text { albicans }\end{array}$ & MY1055 & Target, human pathogen \\
\hline Bacillus subtilis & $\begin{array}{r}\text { ATCC } \\
6633\end{array}$ & Target, human pathogen \\
\hline $\begin{array}{c}\text { Pseudomonas } \\
\text { aeruginosa }\end{array}$ & PAO1 & Target, human pathogen \\
\hline $\begin{array}{l}\text { Staphylococcus } \\
\text { aureus }\end{array}$ & MB5393 & Target, human pathogen \\
\hline $\begin{array}{c}\text { Acinetobacter } \\
\text { baumannii }\end{array}$ & MB5973 & Target, human pathogen \\
\hline $\begin{array}{l}\text { Streptomyces } \\
\text { nodosus }\end{array}$ & $\begin{array}{l}\text { JCM } 4297 \\
\text { (type } \\
\text { strain) }\end{array}$ & Produces amphotericin B \\
\hline $\begin{array}{l}\text { Streptomyces } \\
\quad \text { rimosus }\end{array}$ & $\begin{array}{l}\text { JCM } 4073 \\
\text { (type } \\
\text { strain) }\end{array}$ & Produces oxytetracycline \\
\hline $\begin{array}{l}\text { Streptomyces } \\
\text { rimosus }\end{array}$ & $\begin{array}{l}\text { JCM } 4667 \\
\text { (type } \\
\text { strain) }\end{array}$ & Produces oxytetracycline \\
\hline $\begin{array}{l}\text { Streptomyces } \\
\text { varsoviensis }\end{array}$ & $\begin{array}{l}\text { JCM } 4523 \\
\text { (type } \\
\text { strain) }\end{array}$ & Produces oxytetracycline \\
\hline $\begin{array}{l}\text { Streptomyces } \\
\quad \text { kanamyceticus }\end{array}$ & $\begin{array}{l}\text { JCM } 4775 \\
\text { (type } \\
\text { strain) }\end{array}$ & Produces kanamycin \\
\hline $\begin{array}{l}\text { Streptomyces } \\
\text { venezuelae }\end{array}$ & $\begin{array}{l}\text { JCM } 4526 \\
\text { (type } \\
\text { strain) }\end{array}$ & Produces chloramphenicol \\
\hline $\begin{array}{r}\text { Burkholderia } \\
\text { multivorans }\end{array}$ & F-269,115 & $\begin{array}{l}\text { Produces unknown antifungal } \\
\text { and antibacterial activity on } \\
\text { many culture media }\end{array}$ \\
\hline
\end{tabular}

${ }^{\text {a }}$ Strains designated with MY, MB and F- are maintained in the Fundación MEDINA culture collection

The antibiotic-producing Streptomyces (Table 1) were revived from $10 \%$ frozen glycerol stocks and grown in deepwell 96-well plates (Enzyscreen BV, www.enzyscreen.com) containing GYM broth (glucose $4 \mathrm{~g}$, yeast extract $4 \mathrm{~g}$, malt extract $10 \mathrm{~g}, \mathrm{CaCO}_{3} 2 \mathrm{~g}, \mathrm{pH}$ adjusted to 7.2, per litre of $\mathrm{H}_{2} \mathrm{O}$ ) for 4 days at $28^{\circ} \mathrm{C}$ and $220 \mathrm{rpm}$ on an orbital shaker. Liquid cultures were replicated with a 96-pin plate replicator (Enzyscreen $\mathrm{BV}$ ) onto the surface of $40 \mathrm{ml}$ of four different $2 \%$ agar-containing media (top layer of Janus plates): GYM with $2 \%$ agar, DEF-15 (sucrose $4 \mathrm{~g}, \mathrm{NH}_{4} \mathrm{Cl} 2 \mathrm{~g}$, $\mathrm{Na}_{2} \mathrm{SO}_{4} 2 \mathrm{~g}, \mathrm{~K}_{2} \mathrm{HPO}_{4} 1 \mathrm{~g}, \mathrm{MgCl}_{2} \cdot 6 \mathrm{H}_{2} \mathrm{O} 1 \mathrm{~g}, \mathrm{NaCl} 1 \mathrm{~g}$, $\mathrm{CaCO}_{3} 2 \mathrm{~g}, 1 \mathrm{ml}$ trace element solution [100 mg $\mathrm{MnCl}_{2} \cdot 4 \mathrm{H}_{2} \mathrm{O}, 100 \mathrm{mg} \mathrm{ZnCl}, 100 \mathrm{mg} \mathrm{FeCl}_{2} 4 \mathrm{H}_{2} \mathrm{O}$,
$50 \mathrm{mg} \mathrm{NaI}$ per 1 of $\mathrm{H}_{2} \mathrm{O}$ ], $\mathrm{pH}$ adjusted to 7.0 per litre of $\mathrm{H}_{2} \mathrm{O}$ ); FPY-12 (fructose $20 \mathrm{~g}$, glucose $10 \mathrm{~g}$, maltose $10 \mathrm{~g}$, Bacto Peptone (Becton-Dickinson) $5 \mathrm{~g}$, amicase $5 \mathrm{~g}, 1 \mathrm{ml}$ trace elements $\left[500 \mathrm{mg} \mathrm{FeSO}_{4} \cdot 7 \mathrm{H}_{2} \mathrm{O}\right.$, $500 \mathrm{mg} \mathrm{ZnSO}_{4} \cdot 7 \mathrm{H}_{2} \mathrm{O}, 100 \mathrm{mg} \mathrm{MnSO}_{4} \cdot \mathrm{H}_{2} \mathrm{O}, 50 \mathrm{mg}$ $\mathrm{CuSO}_{4} \cdot 5 \mathrm{H}_{2} \mathrm{O}, 50 \mathrm{mg} \mathrm{CoCl} \cdot 6 \mathrm{H}_{2} \mathrm{O}$ per litre of $\mathrm{H}_{2} \mathrm{O}$, $\mathrm{pH}$ adjusted to 7.0); and $\mathrm{KHC}$ (dextrin from corn type I $20 \mathrm{~g}$, B-cyclodextrin $10 \mathrm{~g}$, double-concentrated tomato paste $20 \mathrm{~g}$, yeast extract $10 \mathrm{~g}, \mathrm{CoCl}_{2} \cdot 6 \mathrm{H}_{2} \mathrm{O} 5 \mathrm{mg}, \mathrm{pH}$ adjusted to 7.2 per litre of $\mathrm{H}_{2} \mathrm{O}$ ).

To test for antifungal activity, a few colonies of Candida albicans were inoculated in $10 \mathrm{ml}$ of Sabouraud dextrose broth (SDB, Becton-Dickinson) and incubated $18-20 \mathrm{~h}$ at $37^{\circ} \mathrm{C}, 220 \mathrm{rpm}$ on an orbital shaker. Optical density $\left(\mathrm{OD}_{660}\right)$ of the overnight inoculum was measured and adjusted to 0.4 , and $30 \mathrm{ml}$ of the inoculum were added to 11 of YNBD agar (6.7 g yeast nitrogen base, $1 \mathrm{~g}$ glucose, $15 \mathrm{~g}$ agar, distilled $\mathrm{H}_{2} \mathrm{O} 11$ ) at $40{ }^{\circ} \mathrm{C}$ (Suay et al. 2000; Bills et al. 2008), which was poured onto the assay layer of the Janus plates.

To test for antibacterial activity, both B. subtilis and $P$. aeruginosa inocula were grown overnight in Luria broth (LB) at $37{ }^{\circ} \mathrm{C}, 220 \mathrm{rpm}$. The $\mathrm{OD}_{600}$ was adjusted to 0.4 in $30 \mathrm{ml}$ of $1.5 \% \mathrm{LB}$ agar at $40{ }^{\circ} \mathrm{C}$ (Suay et al. 2000) and subsequently poured to the assay layer of Janus plates.

Pure antibiotic assays

Two-fold serial dilutions of five antibiotics, four antibacterial (chloramphenicol, $\mathrm{Cm}$; tetracycline, $\mathrm{Tc}$; oxytetracycline, Otc; kanamycin, $\mathrm{Km}$ ) and one antifungal (amphotericin B, AmB), were used to compare how pure antibiotics diffused in the two plate systems (Fig. 2). Cm was dissolved in ethanol, Tc, Otc, and $\mathrm{AmB}$ in $100 \%$ DMSO and $\mathrm{Km}$ in $\mathrm{H}_{2} \mathrm{O}$ before preparing dilution series in ethanol, $20 \%$ DMSO, and $\mathrm{H}_{2} \mathrm{O}$ respectively. Pathogens were unaffected by $20 \%$ DMSO in parallel assays.

Forty $\mathrm{ml}$ of GYM with $2 \%$ agar were poured on the top layer of the Janus plates. After solidifying, $5 \mu \mathrm{l}$ of each dilution of antibiotic were spotted onto the media. The antibiotics were absorbed into the agar for approximately $1 \mathrm{~h}$. The plates were inverted, the platform was removed and the assay layer was poured (30 ml of YNBD with $1.5 \%$ agar containing $C$. albicans or $30 \mathrm{ml}$ of LB with $1.5 \%$ agar containing B. subtilis or P. aeruginosa). 

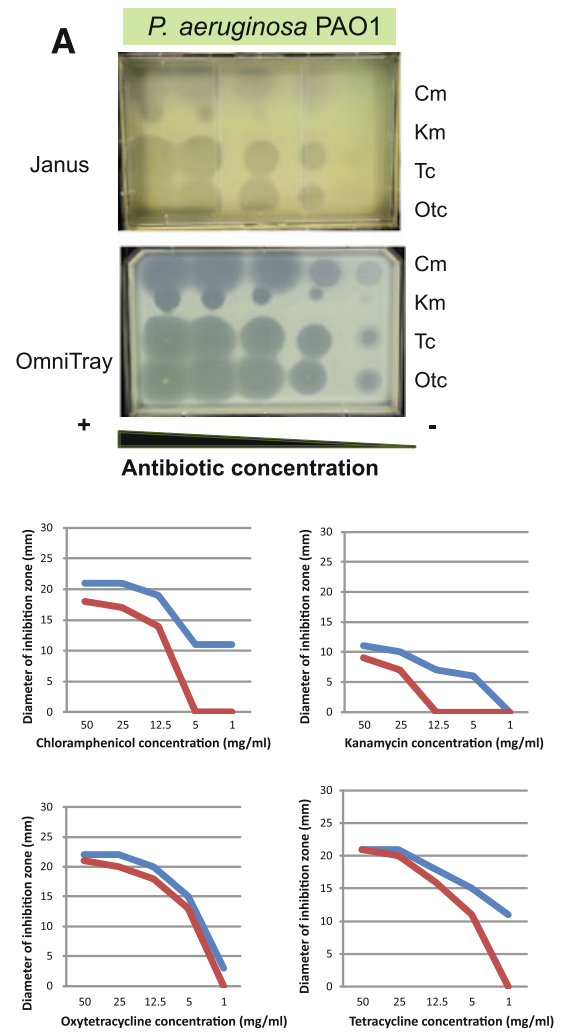
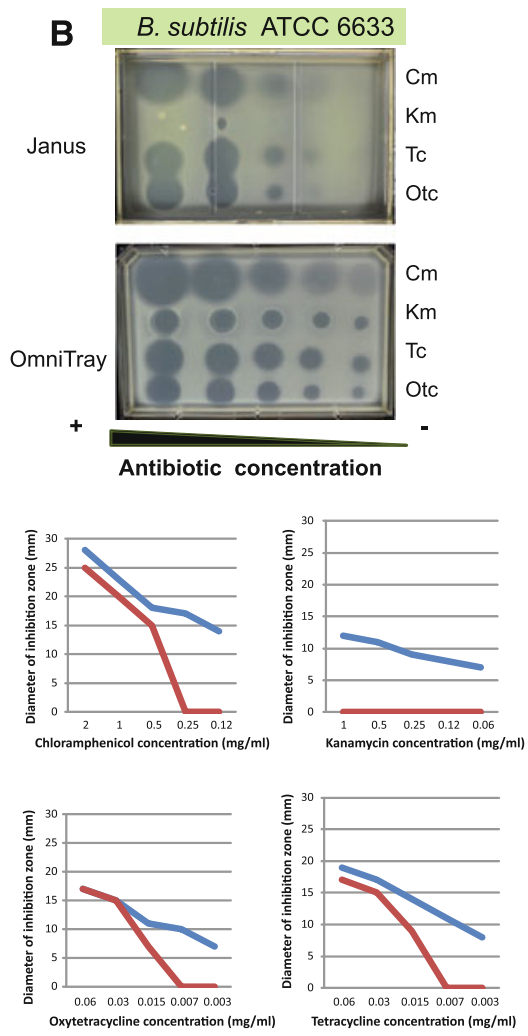

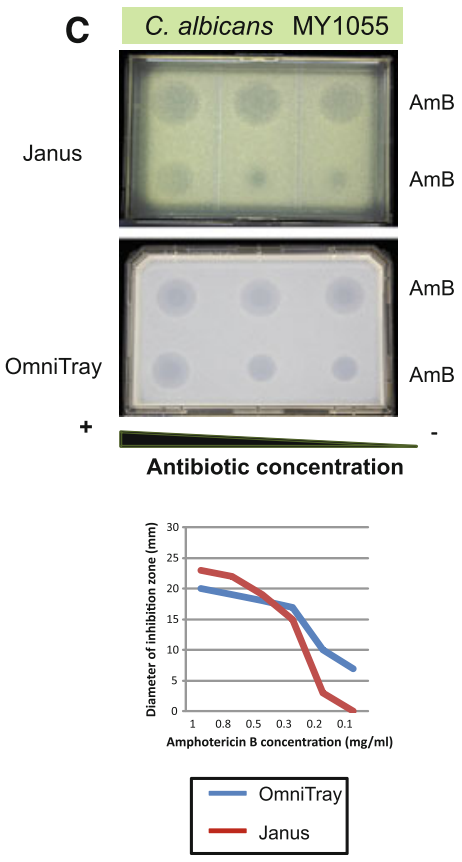

Fig. 2 Different antibiotics dilution series applied to $P$. aeruginosa (a), B. subtilis (b) and C. albicans (c) growing in Janus and OmniTray plates. Photographs of assay plates

In parallel, $40 \mathrm{ml}$ of GYM with $2 \%$ agar containing $C$. albicans or LB with $2 \%$ agar containing B. subtilis or P. aeruginosa were poured into OmniTray plates. After solidification, $5 \mu \mathrm{l}$ of the antibiotic dilutions were spotted on the surface in the same pattern as the Janus plates.

After overnight incubation at $37^{\circ} \mathrm{C}$, the plates were examined and the diameters of ZOIs were measured. All assays and measurements were made in triplicate.

Producing strains assays

Forty $\mathrm{ml}$ of GYM, KHC, DEF-15 and FPY-12 with $2 \%$ agar were poured on the top side of Janus plates. Once this layer solidified, producer strains grown in deepwell plates (see above) were inoculated onto the surface of the top agar layer with a 96-pin plate replicator. Plates were enclosed in plastic bags, and the strains were grown at $30{ }^{\circ} \mathrm{C}$ during five and ten days. (above) correspond to dose-response curves for each antibiotic (below). $\mathrm{Cm}$ chloramphenicol, $\mathrm{Km}$ kanamycin, $\mathrm{Tc}$ tetracycline, Otc oxytetracycline, and $A m B$ amphotericin B

After growth, the plates were inverted, the plastic platform was removed, and the assay layer was poured with either $C$. albicans, B. subtilis, or $P$. aeruginosa as described above. After overnight incubation at $37{ }^{\circ} \mathrm{C}$, the plates were photographed and the diameters of ZOIs were measured. All assays and measurements were made in triplicate.

Mass spectrometry and identification of antibiotics

To prepare agar culture samples for liquid chromatography mass spectrometry (LC-MS) analysis, $5 \mathrm{~mm}$ agar discs with antibiotic-producing bacterial colonies were cut from the upper agar layer with a sterile Transfer Tube (Spectrum Laboratories, Rancho Dominguez, California, USA). For each bacterium, three agar plugs were extracted with an equal volume of $20 \% \mathrm{DMSO}$, and the extract was filtered to prior to LC-MS analysis. 
Metabolite identification was undertaken in a twostep process. The first step used database matching with chromatographic retention time (RT), the UV-visible spectrum, and the positive and negative mass spectra from the extract components. Extract samples $(1 \mu \mathrm{l})$ were analyzed with an Agilent (Santa Clara, CA) 1100 single quadrupole LC-MS, using a Zorbax SB-C8 column $(2.1 \times 30 \mathrm{~mm})$, maintained at $40{ }^{\circ} \mathrm{C}$ and with a flow rate of $300 \mu \mathrm{l} / \mathrm{min}$. Solvent A consisted of $10 \%$ acetronitrile and $90 \%$ water with $1.3 \mathrm{mM}$ trifluoroacetic acid and ammonium formate, and solvent B was $90 \%$ acetronitrile and $10 \%$ water with $1.3 \mathrm{mM}$ trifluoroacetic acid and ammonium formate. The gradient started at $10 \% \mathrm{~B}$ and went to $100 \% \mathrm{~B}$ in $6 \mathrm{~min}$, kept at $100 \% \mathrm{~B}$ for $2 \mathrm{~min}$ and returned to $10 \% \mathrm{~B}$ for $2 \mathrm{~min}$ to initialize the system. Full diode array UV scans from 100 to $900 \mathrm{~nm}$ were collected in $4 \mathrm{~nm}$ steps at $0.25 \mathrm{~s} / \mathrm{scan}$. The eluting solvent was ionized using the standard Agilent 1100 electrospray ionization source adjusted to a drying gas flow of $11 \mathrm{l} / \mathrm{min}$ at $325{ }^{\circ} \mathrm{C}$ and a nebulizer pressure of $40 \mathrm{psig}$. The capillary voltage was set to $3,500 \mathrm{~V}$. Mass spectra were collected as full scans from 150 to $1,500 \mathrm{~m} / \mathrm{z}$, with one scan every $0.77 \mathrm{~s}$, in both positive and negative modes. The DAD spectra, retention time, positive and negative mass spectra of the active samples were searched with an in-house-developed application and compared to the UV-LC-MS data of known metabolites stored in a proprietary database where metabolite standard data had been obtained using the exact same LC-MS conditions as the samples under analysis (Vicente et al. 2009). Further database matches were confirmed by manually comparing UV-visible spectra.

In the case that no reasonable match was obtained, extracts were injected into another Agilent 1200 LC using the same LC parameters as above, and mass spectra were acquired on a Bruker maXis HR-TOF mass spectrometer (Bruker Daltonics $\mathrm{GmbH}$, Bremen, Germany). Ionization of the eluting solvent was obtained using the standard maxis ESI source adjusted to a drying gas flow of $11 \mathrm{l} / \mathrm{min}$ at $200{ }^{\circ} \mathrm{C}$ and a nebulizer pressure of $40 \mathrm{psig}$. The capillary voltage was set to $4,000 \mathrm{~V}$. Mass spectra were collected from 150 to $2,000 \mathrm{~m} / \mathrm{z}$ in positive mode. Database matching compared the retention times and exact masses of sample extract components with the retention times and exact masses captured from authentic samples of known metabolites stored in a database and acquired under identical LC-MS conditions (Vicente et al. 2009) and manually with published data (Buckingham 2011).

High throughput assay of soil bacteria

Soil samples were collected at different altitudes $(1,125-2,311 \mathrm{~m})$ in the Sierra Nevada National Park, Granada, Spain. Fresh soil samples (1 g) were dispersed in $100 \mathrm{ml}$ of sterile diluent (VL70 medium without added growth substrates or vitamins) in 250-ml Erlenmeyer flasks by stirring with a magnetic bar for $30 \mathrm{~min}$. These $10^{-2}$ diluted aliquots were serially diluted to $10^{-6}$. Then $100 \mu$ l of dilutions $10^{-3}-10^{-6}$ were spread (five replicates at each dilution) onto the surface of the isolation media with sterile glass spreading rods. The media used for the isolations were gellan gum-solidified VL70 medium containing as growth substrates (1) D-xylose, $0.05 \%$ $(\mathrm{w} / \mathrm{v})$; or $(2)$ a mixture of peptone-casein, $0.025 \%$ $(\mathrm{w} / \mathrm{v})$ each (Sait et al. 2002; Joseph et al. 2003; Davis et al. 2005). Both media were supplemented with $0.1 \% \mathrm{w} / \mathrm{v}$ cycloheximide to inhibit fungi. Isolation plates were incubated at $18{ }^{\circ} \mathrm{C}$ and $60 \%$ relative humidity in the dark. Bacterial colonies were picked from each dilution plate once a wk, during 5 weeks with an automated colony picking robot (Qpix2, Molecular Devices, New Milton, UK) and then transferred into 96-well tissue culture plates (Corning Inc., Corning, NY, USA) filled with $270 \mu \mathrm{l}$ per well of R2A medium (Becton-Dickinson) (Fig. S1). After 2 weeks of incubation at $18{ }^{\circ} \mathrm{C}, 95$-strain sets of soil strains were transferred from multiwell plates with a 96-pin plate replicator onto the top layer of the Janus plates containing $40 \mathrm{ml}$ of R2A medium (Fig. S1). Burkholderia multivorans F-269,115, a highly antagonistic strain observed to consistently produce strong ZOIs against fungi and bacteria was inoculated in position A1 of assay plates as a positive control (Fig. $\mathrm{S} 1)$. Janus plates were incubated at $18{ }^{\circ} \mathrm{C}$ for 5 days in plastic bags, and then the assay layer was poured with either C. albicans, B. subtilis, or $P$. aeruginosa as described above. After overnight incubation at $30{ }^{\circ} \mathrm{C}$, the plates were examined for ZOIs and photographed. Active colonies were rescued from their corresponding master plates, and the assay was repeated in 24-colony arrays to confirm activity (Fig. S1). Before, proceeding with scale up, newly selected antibiotic- 
producing bacteria were frozen in glycerol $20 \%(\mathrm{v} / \mathrm{v})$ at $-80{ }^{\circ} \mathrm{C}$ for long-term storage (Fig. S1).

DNA extraction, 16S rRNA gene sequence analysis and identification of soil bacteria

Bacterial genomic DNAs were extracted by microwave lysis (Menon and Nagendra 2001). A few colonies of each strain were suspended in $750 \mu \mathrm{l}$ of MilliQ water in a microcentrifuge tube and irradiated at the maximum power in a microwave oven with three pulses of $45 \mathrm{~s}$ alternating with a $30 \mathrm{~s}$ intervals. For amplification of partial 16S rRNA gene sequences, the primer pairs FD1 (5'-AGAGTTTGATCCTGGCTCAG-3') and 1100R (5'-GGGTTGCGCTCGTTG-3') were used. PCR mixtures were composed of $5.0 \mu \mathrm{l}$ PCR buffer $(10 \times)$, $4.0 \mu \mathrm{lgCl}_{2}(25 \mathrm{mM}), 1.0 \mu \mathrm{l}$ dNTPs (10 mM each), $1.0 \mu \mathrm{l}$ each forward and reverse primers $(10 \mu \mathrm{M})$, $0.3 \mu \mathrm{l} \mathrm{Taq}$ polymerase $(5 \mathrm{U} / \mu \mathrm{l}$ Qbiogene) and $5.0 \mu \mathrm{l}$ DNA solution in a total volume of $50 \mu$. The thermal cycling program was described previously (Pascual et al. 2010). PCR products were purified and sequenced using the above primer pairs at Secugen S.L. (Madrid, Spain). The nearest phylogenetic neighbors of the isolates were determined using the EzTaxon-e Database (http://eztaxon-e.ezbiocloud.net/) (Kim et al. 2012).

Culture medium, fermentation and extraction of katanosins from Lysobacter sp.

Inoculum of a ZOI-producing strain Lysobacter sp. F-278,480 was prepared by transferring a loopful of surface growth from R2A agar into a tube with $5 \mathrm{ml}$ R2A broth. The inoculated medium was incubated on a rotary shaker $(220 \mathrm{rpm})$ at $28{ }^{\circ} \mathrm{C}$ for $48 \mathrm{~h}$. The inoculum at $10 \% \mathrm{v} / \mathrm{v}$ was transferred to $10 \mathrm{ml}$ of fermentation medium (yeast extract $4 \mathrm{~g}$, malt extract $10 \mathrm{~g}$ and dextrose $4 \mathrm{~g}$, per 1 of $\mathrm{H}_{2} \mathrm{O}, \mathrm{pH}$ adjusted to 7.0). The culture was fermented at $28{ }^{\circ} \mathrm{C}$ for 3 days on a rotary shaker at $220 \mathrm{rpm}$ (Fig. S1). The fermentation was extracted with an equal volume of acetone amended with $20 \%$ DMSO. Subsequently, the acetone was evaporated under a stream of $\mathrm{N}_{2}$, and the aqueous extract was assayed for growth inhibition of B. subtilis, S. aureus, A. baumannii, P. aeruginosa and C. albicans (Table 1). The active extract was analyzed by LC-HRMS as described above to identify the major metabolites that might contribute to the observed antibiosis.

\section{Results}

Comparative antibiotic assays

ZOIs from pure antibiotics against $P$. aeruginosa in Janus plates were comparable but proportionally smaller in Janus plates compared to those in OmniTray plates (Fig. 2a). The lowest concentration of $\mathrm{Km}$ $(1 \mathrm{mg} / \mathrm{ml})$ was not detectable in Janus plates.

$\mathrm{Cm}, \mathrm{Km}, \mathrm{Tc}$ and Otc were assayed at lower concentrations against the more sensitive B. subtilis (Fig. 2b) than against $P$. aeruginosa because the ZOIs overextended the plates and were unmeasurable. The ZOIs for $\mathrm{Cm} \mathrm{Tc}$, and Otc were slightly smaller in Janus plates than those observed in the OmniTrays at the equivalent concentrations. Detectable concentrations of $\mathrm{Km}$ apparently failed to penetrate into the assay layer of Janus plates (Fig. 2b).

Application of AmB at different concentrations in the first layer of Janus and in OmniTray plates caused comparable ZOIs against $C$. albicans (Fig. 2c). In Janus plates, the diameters of ZOIs were smaller than those detected in OmniTray plates at the lower concentrations (100 and $200 \mu \mathrm{g} / \mathrm{ml})$, but at greater concentrations (between 300 and $1,000 \mu \mathrm{g} / \mathrm{ml}$ ) the diameters were larger.

Producer strains assay

Six Streptomyces reference strains known to produce the same antibiotics as used in the pure compound experiments (Table 1) were replicated in two rows onto the top layer of four different Janus plates containing four kinds of media (Fig. S2, legend). The cultures were grown during 5 and 10 days, and an assay layer incorporating the target strains was added (LB in the case of B. subtilis and P. aeruginosa and YNBD in the case of $C$. albicans, Fig. S2). Rather than each organism producing ZOIs corresponding to its reported antibiotic capacity, we observed an assortment of effects ranging from no growth, non-production, to potent and unexpected off-target antibiosis. As expected, the growth media and duration of incubation colony growth influenced the growth of strains and the intensity of antimicrobial activity caused by each antibiotic-producing strain. No single medium was optimal for detection of antibiosis from all strains.

Streptomyces venezuelae JCM 4526, the Cm producer, grew in the GYM liquid inoculum medium, but 
failed to grow in any of the solid agar media tested in the Janus plates and therefore its position on the growth layer was consistently vacant (Fig. S2). Both strains of Streptomyces rimosus and S. varsoviensis, although not previously reported to produce antifungal metabolites, were strongly active towards $C$. albicans on KHC, FPY-12, and GYM. Subsequent LC-HRMS analysis of agar colony extracts indicated that $S$. rimosus JCM 4073, not only produced oxytetracycline $\left(\mathrm{C}_{22} \mathrm{H}_{24} \mathrm{~N}_{2} \mathrm{O}_{9}\right.$, standard RT $0.73 \mathrm{~min}, \mathrm{~m} / \mathrm{z}$ 460.1474, experimental RT $0.78, \mathrm{~m} / \mathrm{z} 460.1473$ ), but also produced a glycosylated polyene macrolide tentatively identified as rimocidin $\left(\mathrm{C}_{39} \mathrm{H}_{61} \mathrm{NO}_{14}\right.$, calculated $\mathrm{m} / \mathrm{z}$ 767.4092, experimental $\mathrm{m} / \mathrm{z}$ 767.4097, RT $3.60 \mathrm{~min}$ with polyene-like UV spectrum) and a rimocidin analog, known as antibiotic CE108 (PérezZuñiga et al. 2004) $\left(\mathrm{C}_{39} \mathrm{H}_{61} \mathrm{NO}_{14}\right.$, calculated $\mathrm{m} / \mathrm{z}$ 739.3779, experimental $\mathrm{m} / \mathrm{z}$ 739.3788, RT $3.15 \mathrm{~min}$ with polyene-like UV spectrum) that could account for the potent antifungal activity. HRMS analysis of colony extracts of S. kanamyceticus JCM 4775 failed to detect kanamycin $\left(\mathrm{C}_{18} \mathrm{H}_{36} \mathrm{~N}_{4} \mathrm{O}_{11}\right.$, standard $\mathrm{m} / \mathrm{z}$ 484.2380, RT $0.50 \mathrm{~min}$ ), which along with its poor diffusion characteristics in the Janus plates (Fig. 2) would explain why no antibacterial ZO1 was observed from its colonies. Streptomyces nodosus JCM 4297, the AmB producer, generally grew poorly, although it inhibited C. albicans faintly on DEF-15 medium. Whether JCM 4297 contributed to the large ZOIs on GYM was questionable due the strong activity from the adjacent colonies. Most strains grown in DEF-15 medium produced poor antimicrobial activity against $P$. aeruginosa and C. albicans. Colonies of S. rimosus JCM 4667 and JCM 4067 (Otc producers) and S. varsoviensis (Otc producer) caused strong ZOIs

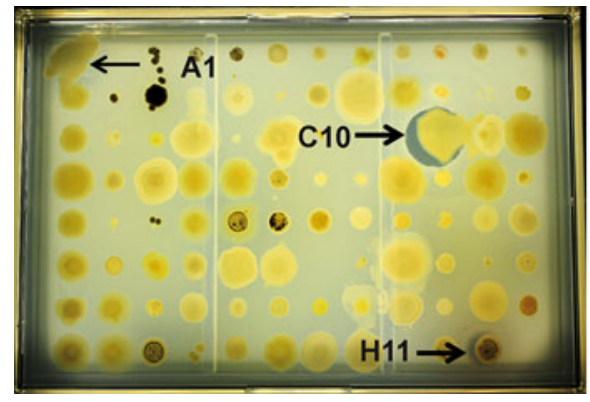

Fig. 3 Zone of inhibition assay of a 96-colony array of wildtype bacteria grown on R2A agar against Bacillus subtilis grown in LB agar. Upper surface view of the growth layer (left) and bottom surface view of assay layer (right). A1, Burkholderia against all three target strains (C. albicans, $P$. aeruginosa and B. subtilis) in KHC, DEF-15, and GYM, but $S$. rimosus JCM 4073 did not inhibit $P$. aeruginosa in KHC medium.

Incubation times of antibiotic-producing organisms influenced the sizes of ZOIs. However, depending on the specific medium-strain combination with larger or smaller ZOIs were evident at 5 or 10 days.

Assays with soil bacteria arrays

A workflow was established starting with isolation of soil bacteria in Petri plates followed by robotic colony picking of bacterial colonies into 96-well master plates (Fig. S1). Master plates were replicated as 95-colony arrays directly into Janus plate assays with position A1 reserved for an antibiotic-producing positive control colony (Fig. 3).

VL70 isolation media supplemented with D-xylose or a mixture of peptone-casein as growth substrates enabled the isolation of bacterial strains belonging to a wide range of taxonomic groups, including actinobacteria, firmicutes, alpha-proteobacteria, beta-proteobacteria, gamma-proteobacteria and bacteroidetes (Table S1). The kinds of bacterial recovered were consistent with previous reports (Janssen et al. 2002; Sait et al. 2002; Joseph et al. 2003; Davis et al. 2005). Unknown and previously uncultured bacteria were also recovered at low frequencies. Two examples were strains F-278,959 and F-278,402, which showed only 97.2 and $96.2 \%$ of 16S rRNA gene similarities with their closest cultivable neighbors, Dyadobacter soli (GQ241324) and Rhizobium sphaerophysae (FJ154088), respectively. The environmental strains were grown in R2A medium in the master plates and on the top layer of Janus plates

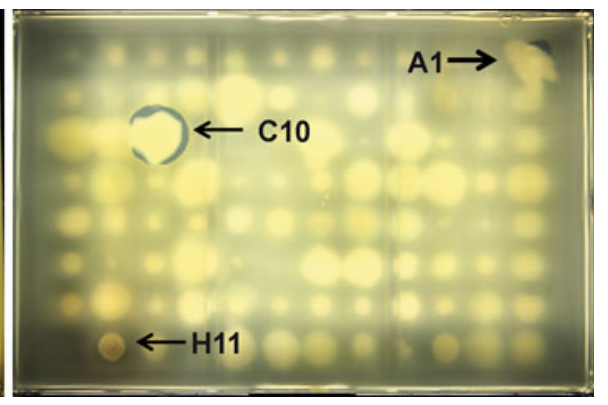

multivorans F-269,115 (positive control) with faint post incubation zone of inhibition; C10, Lysobacter sp. F-278,480, and H11, Streptomyces sp. F-278,462 with distinct zones of inhibition 
because it was a relatively low nutrient medium, albeit more complex than VL70 medium. Parallel attempts to transfer colony arrays to high nutrient media, like trypticase soy agar, often resulted in poor replication, and in some cases, excessive growth and cell swarming. Nearly all bacteria recovered from the VL70 isolation medium were able to grow on R2A medium. Therefore R2A was used for transfer of colonies to 96-well master plates in order to provide cells for replication (Fig. S1) and for the growth medium for colony arrays on the top layer of the Janus plates.

After 5 or 10 days of incubation of the environmental strains and the control strain on the top layer of Janus plates, the target microorganisms were added to the assay layer. Microbial antibiotics or toxins excreted into the medium were detected as clear to diffuse ZOIs radiating from the antibiotic-producing colonies. Because low molecular weight molecules can diffuse freely between both layers, ZOIs could be detected on either the upper side of the first and second agar layers (Fig. 3). However, some false positives caused by colony shadows were evident, but they could be discounted by illuminating true ZOIs on the outer surface of the assay layer with a fluorescent transilluminator.

During preliminary assays of 7,315 colonies, the average number of antibiotic-producing soil isolates causing ZOIs with at least one of the three-pathogen bioassay (the same colony array on each of three Janus plates with a different target pathogens) and totaling 21,945 assays, was $1.6 \%$. The numbers of antibioticproducing filamentous actinobacteria and non-filamentous bacteria detected in Janus plates were 30 $(27.7 \%)$ and $88(72.3 \%)$ respectively. As expected, B. subtilis ATCC 6633 and C. albicans MY1055 were more sensitive targets than P. aeruginosa strain PAO1. No additional antibiotic-producing bacteria were observed or recovered when wild-type strain arrays were incubated for longer periods (10 days) on the top layer of Janus plates.

Figure 3 illustrates a wild-type bacteria array assayed in a Janus plate. A set of environmental strains were arrayed in a 95-matrix, and position A1 was inoculated with a positive control Burkholderia multivorans $\mathrm{F}-269,115$. The target strain in this assay was B. subtilis. After overnight assay incubation, three ZOIs were scored, the positive control (A1), and two wildtype strains identified as Lysobacter sp. F-278,480 (C10) and Streptomyces sp. F-278,462 (H11). The ZOI associated with the Lysobacter sp. F-278,480 was larger than those caused by B. multivorans F-269,115 (positive control) and Streptomyces sp. F-278,462. Colonies of some swarming and gliding bacteria sometimes extended across the R2A agar layer, colonizing larger areas or neighboring bacterial colonies. For example, Lysobacter sp. F-278,480 glided toward a neighbor colony, surrounding and lysing it (Fig. 3), a characteristic trait of Lysobacter species. The Lysobacter and Streptomyces strains were rescued from the master plate, and re-inoculated under the same physical and nutritional conditions in a 24-colony array on a second Janus plate assay (see workflow Fig. S1). The confirmed active strain of Lysobacter sp. F-278,480 was fermented in 10-ml tube fermentations and extracted with acetone. The aqueous extract amended with $20 \%$ DMSO was assayed for antimicrobial activity and analyzed by LC-HRMS. Organic extracts inhibited the growth of $B$. subtilis, S. aureus MRSA and $C$. albicans, but not $P$. aeruginosa PAO1 nor A. baumannii. Dereplication by LC-HRMS (1 ppm mass accuracy as defined by an internal standard) and comparison with published compounds led to the tentative identification of katanosins $A\left(\mathrm{C}_{87} \mathrm{H}_{95} \mathrm{~N}_{15}\right.$ $\mathrm{O}_{17}$, calculated $\mathrm{m} / \mathrm{z}$ 1261.7030, experimental $\mathrm{m} / \mathrm{z}$ 1261.7028, RT $2.98 \mathrm{~min})$ and $\mathrm{B}\left(\mathrm{C}_{58} \mathrm{H}_{97} \mathrm{~N}_{15} \mathrm{O}_{17}\right.$, calculated $\mathrm{m} / \mathrm{z}$ 1275.7187, experimental $\mathrm{m} / \mathrm{z} 1275$. 7188, RT $3.08 \mathrm{~min}$ ). Therefore, antimicrobial activity against Gram positive bacteria was likely attributable to katanosins, also known as lysobactins, cyclic depsipeptides that target bacterial cell wall biosynthesis (Bonner et al. 1988; O'Sullivan et al. 1988; GuzmanMartinez et al. 2007). The extracts components responsible for the $C$. albicans growth inhibition are under investigation.

\section{Discussion}

Because natural products discovery is a factorial process depending the interaction among microorganisms $\times$ growth conditions $\times$ assays (Bode et al. 2002), the ability to replicate colonies across conditions and assay them against different target cells significantly increases the opportunities to detect a metabolite-producing colony. Previously, we have developed prescreening solutions, referred to as nutritional arrays, aimed towards building collections of microorganisms enriched for their capacity to 
produce antibiotics by employing microfermentation systems for fungi and actinomycetes that enabled testing of strain arrays across many media conditions (Bills et al. 2008; Genilloud et al. 2011; Phillips et al. 2011; Roemer et al. 2011). Janus plates can be viewed as a progression towards simplification of high throughput screening systems for bioactive secondary metabolite producing strains that further miniaturizes and eliminates processing steps, while increasing the capacity to evaluate many organisms while varying nutritional, environmental, or assay permutations. This automation-assisted workflow can assess a wide range of bacterial taxonomic groups with the goal of increasing the chances of finding new extracellularly produced cell-perturbing molecules (Fig. S1). The proposed screening paradigm is conceptually similar to an industrialized high throughput system implanted at Cubist Pharmaceutical where large numbers actinomycetes isolates were encapsulated in alginate beads and nascent colonies were massively screened on solid agar surfaces against pathogen strains with engineered resistance genes (Baltz et al. 2008). However detection of antibiotic-producing Streptomyces species from soils would be trivial in Janus plates (Figs. 3, S2). The workflow's utility can be better appreciated by the fact that a single operator (J.P.) could recover and detect a katanosin-producing strain of Lysobacter, a bacterial genus known to be rich in antibiotics but infrequently recovered from soils (Christensen 2005) in a few weeks.

We view the use of the Janus plates as a way to quickly focus valuable fermentation resources on strains with the highest potential for bioactive metabolites, rather than as replacement for traditional discovery-scale fermentations in tubes or flasks. A similar approach has been applied to survey marine bacteria for antibiosis. Thousands of single marine bacterial isolates and replicated sets of marine bacterial isolates were prescreened for inhibitory activity against a single target strain, Vibrio anguillarum, in a single assay condition (glucose and casamino acids agar at $25^{\circ} \mathrm{C}$ ) to select potential antibiotic-producing marine bacteria (Gram et al. 2010; Wietz et al. 2010, 2012). Only strains reproducing the activity on scale up in small volume fermentations were further studied by biological activity and high resolution MS profiling. Prescreening with the Janus plates offers a similar economy of throughput but can be widen the window of opportunity for detecting antibiotics or perturbagens by adding more target organisms and organism-specific growth conditions. Similar economy of scale was gained by using microfermentation systems, especially in the ability to replicate master sets of strains across nutrition or environmental arrays of conditions (Bills et al. 2008; Genilloud et al. 2011). However, the Janus plate system reduces the assay to a near proximity interaction between the excreting colony and the target strain, the need for fermentation and extract processing are postponed until the value of the active microorganisms are confirmed. The workflow outlined herein (Fig. S1) would be advantageous for screening microorganisms in situations where the antibiotic detection is infrequent, e.g., screening for functional molecules against especially when resistant target organisms are sought, e.g., drug resistant Pseudomonas species. Other applications for functional screening of clones from metagenomic libraries (Brady 2007; Craig et al. 2010) or mutation screening during process improvement can be envisaged as well.

Despite the obvious gains in efficiency, throughput and assay flexibility, the Janus plate system, like any in vitro growth system, has its shortcomings. Firstly, growth and an accumulation of a minimal biomass is a prerequisite for detecting a microbial colony's biosynthetic products, and not all bacteria grow well on all agar surfaces, nor do all cells transfer well with pin tools (Fig. S2). Cell-bound antibiotics would not be detected. The dual agar layer increases the diffusion distance, thus as demonstrated in the pure antibiotics experiments, some sensitivity is lost. The system relies on excretion of sufficient antibiotic concentrations for visual detection of growth inhibition or modified phenotypes; therefore, target strain sensitivity and its optical properties are critical. To increase visual sensitivity, one could imagine using pigmented, fluorescent or luminescent strains or reporter strains that change phenotype when a specific target is affected. Antibiotics with poor diffusion characteristics or that spontaneously degrade may be missed, such as was demonstrated with application of pure kanamycin. The composition of the growth layer and incubation will likely profoundly affect antibiotic biosynthesis, and failure to detect antibiosis in one agar medium could be compensated by replicating colony arrays onto multiple media for growth for at different temperatures and times.

In preliminary experiments, we have seen only a few instances of suspected heat-labile antibiosis from 
colonies, presumably caused by lytic enzymes. Possibly sharp changes in $\mathrm{pH}$ and excretion of siderophores could also cause false positives that resemble antibiosis. So far, we have not seen evidence of antibiosis induced by the close proximity of two different bacterial species, but conceivably, in high density colonies, interspecific colony interactions could stimulate production of metabolites not produced in strictly axenic culture, thus introducing false positives. On the other hand, the Janus plates could facilitate a screening strategy directed at monitoring the antibiotics responses to multiple combinations of bacteria grown in close proximity. Some organisms, e.g., Streptomyces species, will likely produce multiple antibiotics. Therefore the use of a Janus plate assay to search for specific antibiotic classes or antibiotics with specific modes of action would need to be carefully designed and interpreted.

The Janus dual agar layer is somewhat frail and must be handled and incubated carefully. When colony arrays were grown during several days, plates were enclosed in plastic bags to prevent desiccation which leads to agar shrinkage and collapse of the growth layer. In our wild colony prescreening example, bacteria from high elevation soils were incubated at $18{ }^{\circ} \mathrm{C}$, so desiccation was inconsequential, but prolonged incubation at warm temperatures $\left(>25^{\circ} \mathrm{C}\right)$ could be problematic. Warmer temperature also will promote swarming and gliding in some kinds of bacteria, and at high colony densities, cross contamination can occur. The double agar layer also can obscure detection and interpretation of weak ZOIs, and ZOIs are most conservatively observed by inspecting the upper surface of the assay layer. Also, large ZOIs may span several adjacent colonies; in this case, all colonies from within the ZOI should be rescued and reconfirmed in a second low density assay. Finally, we advise caution in using two different agar layers that may be nutritionally incompatible or toxic to the target organisms, e.g., high osmotic concentrations of salts or sugars that would inhibit growth of the target pathogen.

\section{Conclusions}

Antimicrobial assays in two opposed agar layers formed in Janus plates behaved similarly to parallel antibiotic assays in singe agar layers in OmniTray plates. The
Janus plates facilitated a workflow for prescreening large populations of wild colonies of bacteria for cellperturbing small molecules, e.g., antibiotics. Bacterial colonies recovered on specialized isolation media can be transferred to 96-wells plates with a robotic colony picker. Once grown in 96-well master plates, sets of colonies can be factorially replicated onto Janus plates with different nutrient media in the top growth layer. A separate growth layer means plates can be incubated at varied time intervals and conditions to stimulate excretion of bioactive molecules. Once grown, replicated colony arrays can be assayed against multiple target cells in the opposed assay layer. ZOIs or other phenotypic changes in the target organisms guide selection of those bacteria capable of excreting cell-perturbing small metabolites which are then accumulated for more elaborate fermentations aimed at stimulating, evaluating and identifying those molecules.

Acknowledgments This research was supported by the Spanish Ministry of Science and Innovation's ConsoliderIngenio Program cofinanced with FEDER support from the European Union (Project CSD2007-00005) and its Non-Oriented Basic Research Program (Project SAF2010-15010). We thank Pieter van Dillewijn, Zaidín Experimental Station, CSIC, and the administration of the Sierra Nevada National Park for assistance and permission for collecting soils. Jesús L. Romalde, Michael A. Goetz and Dwight Baker and the anonymous reviewers made helpful comments on the manuscript. We would like to express our gratitude to our former coworkers and colleagues at Merck Research Laboratories who supported the development of the Janus plates.

Open Access This article is distributed under the terms of the Creative Commons Attribution License which permits any use, distribution, and reproduction in any medium, provided the original author(s) and the source are credited.

\section{References}

Anonymous (1977) Report of the World Health Organization Expert Committee on Antibiotics. Geneva, Switzerland

Baltz RH, Monahan C, Murphy C, Penn J, Ritz D, Wrigley S (2008) Methods and compositions for ultra-high throughput screening of natural products. U.S. Patent Application Publication 2008/0318267A1

Bauer AW, Kirby WMM, Sherris JC, Turck M (1988) Antibiotic susceptibility testing by a standardized single disk method. Am J Clin Pathol 45:493-496

Bills GF, Platas G, Fillola A, Jiménez MR, Collado J, Vicente F, Martín J, González A, Bur-Zimmermann J, Tormo JR, Peláez F (2008) Enhancement of antibiotic and secondary 
metabolite detection from filamentous fungi by growth on nutritional arrays. J Appl Microbiol 104:1644-1658

Blom H, Katla T, Hagen BF, Axelsson L (1997) A model assay to demonstrate how intrinsic factors affect diffusion of bacteriocins. Int J Food Microbiol 38:103-109

Bode HB, Bethe B, Höfs R, Zeek A (2002) Big effects from small changes: possible ways to explore nature's chemical diversity. ChemBioChem 3:619-627

Bonner DP, O'Sullivan J, Tanaka SK, Clark JM, Whitney RR (1988) Lysobactin, a novel antibacterial agent produced by Lysobacter sp. II. Biological properties. J Antibiot 41: 1745-1751

Brady SF (2007) Construction of soil environmental DNA cosmid libraries and screening for clones that produce biologically active small molecules. Nat Protoc 2: 1297-1305

Brown LR (1982) Antibiotic testing vessel. U.S. Patent $4,326,028$

Buckingham J (2011) Dictionary of natural products on DVD. CRC Press, Boca Raton

Christensen P (2005) Genus IV. Lysobacter Christensen and Cook 1978. In: Brenner D, Krieg N, Staley J, Garrity GM (eds) Bergey's manual of systematic bacteriology, 2nd edn, vol 2. New York, pp 95-101

Colwell FS, Speidel HK (1985) Diffusion through a doublesided plate-development of a method to study algabacterium interactions. Appl Environ Microbiol 50: 1357-1360

Craig JW, Chang FY, Kim JH, Obiajulu SC, Brady SF (2010) Expanding small-molecule functional metagenomics through parallel screening of broad-host-range cosmid environmental DNA libraries in diverse proteobacteria. Appl Environ Microbiol 76:1633-1641

Davies J (1990) What are antibiotics? Archaic functions for modern activities. Mol Microbiol 4:1227-1231

Davies J, Ryan KS (2011) Introducing the parvome: bioactive compounds in the microbial world. ACS Chem Biol (in press)

Davies J, Spiegelman GB, Yim G (2006) The world of subinhibitory antibiotic concentrations. Curr Opin Microbiol 9:445-453

Davis KER, Joseph SJ, Janssen PH (2005) Effects of growth medium, inoculum size, and incubation time on culturability and isolation of soil bacteria. Appl Environ Microbiol 71:826-834

Donadio S, Monciardini P, Sosio M (2007) Polyketide synthases and nonribosomal peptide synthetases: the emerging view from bacterial genomics. Nat Prod Rep 24:1073-1109

Furumai T, Kakinuma S, Yamamoto H, Komiyama N, Suzuki K, Saitoh K, Oki T (1993) Biosynthesis of the pradimicin family of antibiotics. I. Generation and selection of pradiminnon producing mutants. J Antibiot 46:412-418

Genilloud O, González I, Salazar O, Martín J, Tormo JR, Vicente F (2011) Current approaches to exploit actinomycetes as a source of novel natural products. J Ind Microbiol Biotechol 38:375-389

Gram L, Melchiorsen J, Bruhn JB (2010) Antibacterial activity of marine culturable bacteria collected from a global sampling of ocean surface waters and surface swabs of marine organisms. Marine Biotechnol 12:439-451

Gratia A (1947) Techniques sélectives pour la recherche systématique dans la nature de micro-organismes doués, soit de propriétés antibiotiques, soit de propriétés antibactériophages, soit de propriétés antagonistes des antibiotiques. Bull Soc Chim Biol 29:352-354

Gratia A, Fredericq P (1946) Diversité des souches antibiotiques de $E$. coli et étendue variable de leur champs d'action. Comp Rend Soc Biol 140:1032-1033

Gross H, Loper JE (2009) Genomics of secondary metabolite production by Pseudomonas spp. Nat Prod Rep 26: $1408-1446$

Guzman-Martinez A, Lamer R, VanNieuwenhze MS (2007) Total synthesis of lysobactin. J Am Chem Soc 129: 6017-6021

Hayakawa M, Yoshida Y, Iimura Y (2004) Selective isolation of bioactive soil actinomycetes belonging to the Streptomyces violaceusniger phenotypic cluster. J Appl Microbiol 96: 973-981

Janssen PH, Yates PS, Grinton BE, Taylor PM, Sait M (2002) Improved culturability of soil bacteria and isolation in pure culture of novel members of the divisions Acidobacteria, Actinobacteria, Proteobacteria, and Verrucomicrobia. Appl Environ Microbiol 68:2391-2396

Joseph SJ, Hugenholtz P, Sangwan P, Osborne CA, Janssen PH (2003) Laboratory cultivation of widespread and previously uncultured soil bacteria. Appl Environ Microbiol 69:7210-7215

Kang DH, Siragusa GR (1999) Agar underlay method for recovery of sublethally heat-injured bacteria. Appl Environ Microbiol 65:5334-5337

Kekessy DA, Piguet JD (1970) New method for detecting bacteriocin production. Appl Microbiol 20:282283

Kim OS, Cho YJ, Lee K, Yoon SH, Kim M, Na H, Park SC, Jeon YS, Lee JH, Yi H, Won S, Chun J (2012) Introducing EzTaxon-e: a prokaryotic 16S rRNA gene sequence database with phylotypes that represent uncultured species. Int J Syst Evol Microbiol 62:716-721

Lamb J (2007) The connectivity map: a new tool for biomedical research. Nat Rev Cancer 7:54-60

Menon PK, Nagendra A (2001) Comparison of rapid method of DNA extraction using microwave irradiation with conventional phenol chloroform technique for use in multiplex PCR for mec A and fem B genes to identify genotypes of MRSA from cultures. Med J Armed Forces India 57: 94-196

Nkanga E-J, Hagedorn C (1978) Detection of antibiotic-producing Streptomyces inhabiting forest soils. Antimicrobiol Agents Chemother 14:51-59

O'Sullivan J, McCullough JE, Tymiak AA, Kirsch DR, Trejo WH, Principe PA (1988) Lysobactin, a novel antibacterial agent produced by Lysobacter sp. I. Taxonomy, isolation and partial characterization. J Antibiot 41: 1740-1744

Pascual J, Macián MC, Arahal DR, Garay E, Pujalte MJ (2010) Multilocus sequence analysis of the central clade of the genus Vibrio by using 16S rRNA, recA, pyrH, rpoD, gyrB, rctB, and toxR genes. Int $J$ Syst Evol Microbiol 60: 154-165

Pérez-Zuñiga FJ, Seco EM, Cuesta T, Degenhardt F, Rohr J, Vallín C, Iznaga Y, Pérez ME, González L, Malpartida F (2004) CE-108, a new macrolide tetraene antibiotic. J Antibiot 57:197-204 
Phelan VV, Liu WT, Pogliano K, Dorrestein PC (2012) Microbial metabolic exchange-the chemotype-to-phenotype link. Nat Chem Biol 8:26-35

Phillips JW, Goetz MA, Smith SK, Zink DL, Polishook J, Onishi R, Salowe S, Wiltsie J, Allocco J, Sigmund J, Dorso K, Lee S, Skwish S, de la Cruz M, Martín J, Vicente F, Genilloud O, Lu J, Painter RE, Young K, Overbye K, Donald RGK, Singh SB (2011) Discovery of kibdelomycin, a potent new class of bacterial type II topoisomerase inhibitor by chemical-genetic profiling in Staphylococcus aureus. Chem Biol 18:955-965

Rios JL, Recio MC, Villar A (1988) Screening methods for natural products with antimicrobial activity - a review of the literature. J Ethnopharmocol 23:127-149

Roemer T, Xu D, Singh SB, Parish CA, Harris GHW, Davies JE, Bills GF (2011) Confronting the challenge of natural product-based antifungal discovery. Chem Biol 18: 148-164

Sait M, Hugenholtz P, Janssen PH (2002) Cultivation of globally distributed soil bacteria from phylogenetic lineages previously only detected in cultivation-independent surveys. Environ Microbiol 4:654-666

Shnit-Orland M, Kushmaro A (2009) Coral mucus-associated bacteria: a possible first line of defense. FEMS Microbiol Ecol 67:371-380

Somkuti GA, Steinberg DH (2002) Agarose/agar assay system for the selection of bacteriocin-producing lactic fermentation bacteria. Biotechnol Lett 24:303-330

Suay I, Arenal F, Asensio FJ, Basilio A, Cabello MC, Díez MT, García JB, del Val AG, Gorrochategui J, Hernández P, Peláez F, Vicente F (2000) Screening of basidiomycetes for antimicrobial activities. Anton Van Leeuwenhoek 78: 129-139

Udwary DW, Gontang EA, Jones AC, Jones CS, Schultz AW, Winter JM, Yang JY, Beauchemin N, Capson TL, Clark BR, Esquenazi E, Eustáquio AS, Freel K, Gerwick L, Gerwick WH, Gonzalez D, Liu W-T, Malloy KL, Maloney KN, Nett M, Nunnery JK, Penn K, Prieto-Davo A, Simmons TL, Weitz S, Wilson MC, Tisa LS, Dorrestein PC, Moore BS (2011) Significant natural product biosynthetic potential of actinorhizal symbionts of the genus Frankia, as revealed by comparative genomic and proteomic analyses. Appl Environ Microbiol 77:3617-3625

Vicente F, Basilio A, Platas G, Collado J, Bills GF, González del Val A, Martín J, Tormo JR, Harris GH, Zink DL, Justice M, Nielsen Kahn J, Peláez F (2009) Distribution of the antifungal agents sordarins across filamentous fungi. Mycol Res 113:754-770

Wietz M, Mansson M, Gotfredsen CH, Larsen TO, Gram L (2010) Antibacterial compounds from marine Vibrionaceae isolated on a global expedition. Marine Drugs 8: 2946-2960

Wietz M, Mansson M, Bowman JS, Blom N, Ng Y, Gram L (2012) Wide distribution of closely related, antibioticproducing Arthrobacter strains throughout the Arctic Ocean. Appl Environ Microbiol 78:2039-2042

Williams ST, Goodfellow M, Alderson G, Wellington EMH, Sneath PHA, Sackin MJ (1983) Numerical classification of Streptomyces and related genera. J Gen Microbiol 129: 1743-1813

Yim G, Wang HH, Davies J (2007) Antibiotics as signaling molecules. Phil Trans R Soc B Biol Sci 362:1195-1200 